\title{
A Porto Alegre do século XIX sob o olhar dos viajantes.
}

\author{
Sheila Katiane Staudt*
}

\begin{abstract}
Resumo: Este trabalho tem por objetivo analisar a forma de olhar dos viajantes sobre a cidade de Porto Alegre no século XIX. Os viajantes que aqui estiveram enxergavam a cidade sob o influxo da nova sensibilidade a que estavam submetidos, e, por isto mesmo, a percebiam sob a ótica do estranhamento, vinculada à barbárie e, portanto, distante da preconizada modernidade. A partir da análise dos recortes de crônicas de viagem contidos no livro intitulado: Os viajantes olham Porto Alegre, de Valter Noal Filho e Sérgio Franco, pretende-se entender o olhar singular lançado pelos viajantes sobre esta cidade que se encontrava em plena formação no período, bem como perceber o processo de construção das imagens de Porto Alegre em diferentes relatos de viagem. Como base teórica recorremos às obras: Fisiognomia da Metrópole Moderna, de Willi Bolle e O Imaginário da Cidade: visões literárias do urbano Paris, Rio de Janeiro, Porto Alegre, de Sandra Pesavento.
\end{abstract}

\begin{abstract}
This work intends to analyze how the travelers looked at Porto Alegre city in the 19th century. The travelers who stayed here looked at the city through the new sensibility to which they were used at the time and, for this reason, they perceived it with surprise, as something close to barbarity and, therefore, far away from the desired modernity. Starting by the analysis of the excerpts of travel narratives published in the book entitled $O s$ viajantes olham Porto Alegre, by Valter Noal Filho and Sérgio Franco, we try to understand the singular look they had at this city which was under development at the time, as well as to perceive the construction process of the images of Porto Alegre in different narratives. Our theoretical support was based on the studies by Willi Bolle in his book Fisiognomia da Metrópole Moderna and also on the book $O$ Imaginário da Cidade: visões literárias do urbano - Paris, Rio de Janeiro, Porto Alegre by Sandra J. Pesavento.
\end{abstract}

Keywords: city, alterity, travel.

Havia na Europa, desde fins do século XVIII, uma preocupação em transformar o espaço urbano devido às aglomerações nos grandes centros. O século XIX destaca-se por acelerar este processo que se iniciara, visto que era necessário resolver o problema do congestionamento nas grandes capitais européias; problema este que inquietava arquitetos e urbanistas no que se refere às questões de ordem higiênica e estética de cidades como Paris, Londres, Roma, Berlim, etc.

A cidade de Paris foi pioneira neste sentido. Maxime Du Camp nos mostra a precária situação da capital francesa nesta época, razão pela qual, melhorias urbanas deveriam ser feitas imediatamente, a fim de torná-la um espaço, no mínimo, habitável:

Após 1848, Paris estava na iminência de se tornar inabitável. A constante expansão da rede ferroviária (...) acelerava o tráfego e o aumento populacional da cidade. As pessoas sufocavam

\footnotetext{
${ }^{*}$ Mestranda UFRGS.
} 
nessas velhas ruelas estreitas, sujas, confusas, em que se apertavam como gado encurralado por não haver outra solução." (DU CAMP apud BENJAMIN, 1985, p.109)

No decorrer do século XIX, os inúmeros viajantes que percorreram o Brasil, os quais na sua maioria europeus, olhavam as cidades brasileiras sob o influxo desta nova sensibilidade a que estavam submetidos, e por isto mesmo, percebiam-nas sob a ótica do estranhamento, vinculadas à barbárie e, portanto, distante da preconizada modernidade.

Segundo a historiadora Sandra Pesavento, "a cidade é o objeto de múltiplos discursos e olhares, que não se hierarquizam, mas que se justapõem, compõem ou se contradizem, sem, por isso, serem uns mais verdadeiros ou importantes que os outros" (PESAVENTO, 2002, p. 9). Dessa forma, entendemos ser válido o estudo sobre as diversas percepções e representações da cidade de Porto Alegre por meio do discurso de viajantes que aqui estiveram, pois na condição de "estrangeiros do lugar", possuíam um olhar arguto que lhes possibilitava refletir sobre culturas, hábitos e costumes tão estranhos aos seus.

Através das reflexões de Lucrécia Ferrara é possível compreender a questão do processo de construção das imagens das cidades:

As transformações econômico-sociais deixam na cidade marcas e sinais que contam uma história não verbal pontilhada de imagens, de máscaras, que tem como significado o conjunto de valores, usos e hábitos, desejos e crenças que misturam, através do tempo, o cotidiano dos homens. (FERRARA apud PESAVENTO, 2002, p.15)

Assim, percebemos que toda e qualquer mudança sofrida por uma cidade deixa marcas em sua fisionomia e, no século XIX, o advento do progresso e o desenvolvimento de Porto Alegre deixaram marcas em seu traçado e, por esta razão, o registro destas modificações está presente nas crônicas dos viajantes que por ela passaram, dando origem, então, às primeiras imagens desta cidade.

Na primeira metade do século XIX, percebemos que a descrição da natureza era recorrente nesses relatos de viagem, já que Porto Alegre estava em plena formação no período. Os aspectos urbanos são enfatizados a partir da segunda metade do século XIX, pois é neste período que as transformações econômicas e estéticas começam a elevá-la à condição de metrópole.

Percebemos a admiração do viajante suíço Heinrich Trächsler que esteve em Porto Alegre em 1828, pelo panorama natural da cidade, aspecto este recorrente em muitas crônicas de viagem do mesmo período:

A cidade de Porto Alegre situa-se sobre uma elevação e proporciona aos olhos uma surpreendente e encantadora visão no meio de duas grandes enseadas, [...] Vê-se o ancoradouro repleto de navios; as ilhas e o serpentear dos cinco rios que se apresentam aos olhos como os cinco dedos de uma mão aberta; os sítios de lazer; [...] Isso tudo, minha frágil pena não consegue descrever com precisão seu valor e grandiosidade, porém, as almas sensíveis, ao 
contemplar estas cenas da natureza, vêem-se transportadas para uma amena, indescritível e deliciosa sensação. (TRÄCHSLER apud NOAL FILHO e FRANCO, 2004, p. 60)

O viajante naturalista Auguste de Saint-Hilaire passou por Porto Alegre em 1820 e percebe a cidade através de um olhar impregnado pelas exigências européias:

Surpreendeu-me o movimento desta cidade, bem como o grande número de edifícios de dois andares e a grande quantidade de brancos aqui existentes. [...] Percebe-se logo que Porto Alegre é uma cidade muito nova. Todas as casas são novas e muitas estão ainda em construção. Mas, depois do Rio de Janeiro não vi cidade tão suja, talvez mesmo mais suja que a metrópole. (SAINT-HILAIRE apud NOAL FILHO e FRANCO, 2004, p. 39)

O aspecto sujo da cidade choca o viajante que tinha como modelo a Europa e, no caso específico de Saint-Hilaire, a cidade de Paris, a qual estava passando por profundas mudanças e benfeitorias em sua estrutura urbana, principalmente no que concerne ao saneamento. De acordo com os estudos de Pesavento (2002), a noção de cidade aberta preconizada por médicos higienistas e reformadores da urbe, já estava em questão desde antes do período haussmaniano na capital francesa. (cf. PESAVENTO, 2002, p.57)

O calçamento precário das ruas da cidade no início do século não passa despercebido pelos viajantes e a presença de alguns edifícios atrai o olhar de inúmeros deles, como é o caso do viajante português Antônio José Gonçalves Chaves:

A cidade de Porto Alegre, Alacriportus, que é a capital da província, está vantajosamente situada junto à confluência de cinco formosíssimos rios, todos navegáveis, [...] As ruas são sofrivelmente alinhadas e niveladas o melhor possível, mas as calçadas não são bem construídas por não haver bons calceteiros, remediando a falta com pedreiros de alvenaria [...] Entre todos os edifícios públicos, o que dá mais na vista é o Hospital da Caridade, [...] Há também principiada a igreja das Dores, sob um risco excelente, tal que só a capela-mor, em que já se celebra missa, representa o corpo de uma grande igreja. (CHAVES apud NOAL FILHO e FRANCO, 2004, p. 39)

O fato de ser uma cidade em formação e não possuir atrativos aos exigentes olhos europeus fazia com que muitos relatos anteriores a 1850 mostrassem o desprezo de alguns viajantes pelo local visitado. O dinamarquês Heinrich Belmann, em 1826, lança um olhar indiferente sobre a capital gaúcha:

[Porto Alegre] não é muito grande, tem aproximadamente 10.000 habitantes e se divide em Cidade Alta e Cidade Baixa. [...] A própria cidade aliás não oferece nada de peculiarmente interessante, a não ser diversos edifícios particulares bem bonitos. (BELMANN apud NOAL FILHO e FRANCO, 2004, p. 54)

A comparação - um dos procedimentos retóricos presentes nos relatos de viagem conforme nos mostra os estudos de François Hartog (1999) - serve como um meio através do qual esses cronistas avaliavam o diferente, tendo como referência o seu próprio local de origem, ou então, locais por eles antes visitados. A exemplo disso, temos a aproximação de localidades européias com paisagens de Porto Alegre: 
Eis-nos:transportados à pequena capital de uma grande província do Brasil, a duas mil léguas mais ou menos do centro ardente da civilização. As luzes só chegam a nós por reflexão. [...]Vede que céu, e que sítios! É o céu da Itália! São os sítios e a vegetação da Provença! Estamos em Porto Alegre! (ARSÈNE ISABELLE apud NOAL FILHO e FRANCO, 2004, p. 71)

Os costumes dos habitantes de Porto Alegre também eram enfatizados pelos viajantes. Ao compararmos a situação brasileira do período com os princípios de educação européia, o desinteresse cultural da população da cidade era tido como um hábito bárbaro:

Só havia escolas primárias-elementares em Porto Alegre, quando por ali passei, entretanto, um português da Europa (Sr. Gomes), juntamente com um jovem belga (Sr. Giélis), acabavam de estabelecer uma escola primária-superior. O talento e o zelo desses professores contribuirão, com certeza, a despertar o gosto pela ciência, adormecido, geralmente, sob uma paixão desenfreada pelo jogo e pela depravação. (ARSÈNE ISABELLE apud NOAL FILHO e FRANCO, 2004, p. 71)

Por possuírem, em sua maioria, a Europa como modelo e referência natural, esses viajantes não deixam de cotejar os costumes lá praticados com as novidades vistas além-mar.

Os primeiros indícios de progresso na capital do Rio Grande do Sul começam a surgir nas crônicas dos viajantes da segunda metade do século XIX. Na Europa, a preocupação com a higiene e com o saneamento urbano já vinha sendo prioridade mesmo antes do governo Haussmann em Paris, governo este que serviu como modelo de progresso e embelezamento urbano a várias cidades européias. Por isso, entendemos o elogio do viajante belga A. Baguet à iniciativa do Conde de Caxias quanto à higienização e afastamento dos cemitérios do centro da cidade, que denota a chegada da modernização para Porto Alegre:

Porto Alegre é uma cidade bem moderna e existe há apenas poucos anos. [...] Antes de deixar a capital da Província de Rio Grande, não esqueçamos de mencionar que o presidente Conde de Caxias fundou ali um cemitério extramuros. Porto Alegre é uma das raras cidades do Brasil dotadas de um estabelecimento tão indispensável do ponto de vista higiênico. (BAGUET apud NOAL FILHO e FRANCO, 2004, p. 82-83)

Henry Lange - viajante alemão - enumera os meios de transporte aqui existentes e o interesse cultural da população - características estas da preconizada modernidade:

A cidade possui linhas ferroviárias e de navegação a vapor, bonde de tração animal, teatro, jornais, enfim tudo o que caracteriza uma cidade grande de futuro. Também as medidas para elevar o nível de cultura intelectual, tanto as brasileiras como as alemãs, começam a aumentar e a melhorar.

Nos últimos tempos foram fundadas algumas louváveis instituições de ensino por hábeis professores alemães. (LANGE apud NOAL FILHO e FRANCO, 2004, p. 188)

O médico português Antônio Lopes Mendes passa por Porto Alegre em 1882 e discorre sobre o desenvolvimento da mesma:

A cidade de Porto Alegre, de qualquer lado que se contemple, oferece um aspecto encantador. [...] As ruas, calçadas de granito e com passeios de grés, são largas, cortam-se em ângulos retos e prolongam-se na direção dos quatro pontos cardeais. As praças são arborizadas e adornadas de vistosos chafarizes monumentais de ferro e mármore, que abastecem a cidade com água potável, que vem do arroio denominado Dilúvio; todas elas são iluminadas a gás, tendo amplas 
lojas de comércio nos principais arruamentos. (MENDES apud NOAL FILHO e FRANCO, 2004, p.196)

Diferentes melhorias urbanas são destacadas por este viajante português como, por exemplo, o calçamento das ruas e a disposição ordenada das mesmas, a qualidade da água nas fontes localizadas nas praças, com finalidade de embelezamento estético da cidade, a iluminação a gás destes locais de lazer citadino, bem como a variedade do comércio local símbolo do capitalismo do mundo moderno.

O americano George William Peterkin relata em sua crônica as marcas da modernização na cidade em 1893:

As ruas parecem-se mais com ruas americanas, isso é, como se as coisas estivessem acontecendo. [...] Tem cerca de 50 mil habitantes ou mais, muitas evidências de progresso: linhas de bondes sendo estendidas, casas novas na parte central e nos subúrbios, casas de negócios e fábricas sendo construídas; o crescimento é muito notável. [...] Sua localização é fantástica, bonita e conveniente. Bons rios convergem para ela e tem duas linhas ferroviárias. (PETERKIN apud NOAL FILHO e FRANCO, 2004, p. 37)

Para este viajante, o modelo de desenvolvimento americano serve como um protótipo a ser seguido pelas cidades em vias de modernização. A semelhança entre as ruas de Porto Alegre com ruas americanas aponta para um caminho acertado a ser seguido no que se refere ao crescimento desta cidade de acordo com o ponto de vista deste viajante.

Com a análise realizada foi possível termos contato com as primeiras imagens da cidade de Porto Alegre, bem como vermos como foi feita a construção das mesmas nos relatos dos viajantes que por ela passaram no século XIX.

A diferença entre as crônicas da primeira e da segunda metade do século em questão é crucial para entendermos a chegada do progresso à capital gaúcha. $\mathrm{O}$ olhar privilegiado desses viajantes deixa à mostra detalhes acerca de inúmeros aspectos citadinos, muitas vezes, não percebidos pelos habitantes locais.

Até 1850, o relato desses viajantes destacava, em grande parte, a natureza e a paisagem campestre da cidade e aproximando a mesma da barbárie, já que não possuía indícios significativos de desenvolvimento. Entretanto, a partir de 1850, estas crônicas começam a salientar o espaço urbano e a cidade propriamente dita, com seu comércio, meios de transporte, melhorias urbanas, etc., qualidades estas que evidenciam não só a expansão urbana de Porto Alegre, como também a mudança de seus costumes, antes tidos como bárbaros e primitivos para um comportamento moderno e civilizado. 


\section{Referências}

BENJAMIN, Walter. Walter Benjamin. São Paulo: Ática, 1985. p. 44-122: A Paris do Segundo Império em Baudelaire.

BOLLE, Willi. Fisiognomia da metrópole moderna. São Paulo: EDUSP, 2000.

HARTOG, François. O espelho de Heródoto: ensaio sobre a representação do outro. Belo Horizonte: Ed. da UFMG, 1999. p. 225-314.

NOAL FILHO, Valter Antonio \& FRANCO, Sergio Costa. Os viajantes olham Porto Alegre. Porto Alegre: Anaterra, 2004. 2 vls.

PESAVENTO, Sandra Jatahy. $O$ imaginário da cidade: visões literárias do urbano - Paris, Rio de Janeiro, Porto Alegre. Porto Alegre: Editora da Universidade/UFRGS, 2002. 